Article

\title{
Global Reach of an Internet Smoking Cessation Intervention among Spanish- and English-Speaking Smokers from 157 Countries
}

\author{
Alinne Z. Barrera ${ }^{1}$, Eliseo J. Pérez-Stable ${ }^{2,3}$, Kevin L. Delucchi ${ }^{4}$ and Ricardo F. Muñoz ${ }^{1, *}$ \\ 1 University of California, San Francisco, San Francisco General Hospital, Department of Psychiatry, \\ 1001 Potrero Avenue, Suite 7M, Box 0852, San Francisco, CA 94110, USA; \\ E-Mail: alinne.barrera@ucsf.edu \\ 2 University of California, San Francisco, Division of General Internal Medicine, 400 Parnassus \\ Avenue, Suite 405, San Francisco, CA 94143, USA; E-Mail: eliseops@medicine.ucsf.edu \\ 3 University of California, San Francisco, Helen Diller Family Comprehensive Cancer Center, Box \\ 0128, San Francisco, CA 94143, USA \\ 4 University of California, San Francisco, Department of Psychiatry, Box 0984, LPPI TRC, San \\ Francisco, CA 94143, USA; E-Mail: kdelucchi@1ppi.ucsf.edu
}

* Author to whom correspondence should be addressed; E-Mail: ricardo.munoz@ucsf.edu;

Tel.: +1-415-206-5214; Fax: +1-415-206-8942

Received: 30 December 2008 / Accepted: 19 February 2009 / Published: 26 February 2009

\begin{abstract}
This investigation is a secondary analysis of demographic, smoking, and depression information in a global sample of Spanish- and English-speaking smokers who participated in a series of randomized controlled smoking cessation trials conducted via the Internet. The final sample consisted of 17,579 smokers from 157 countries. Smoking profiles were similar across languages and world regions and consistent with characteristics of participants in traditional smoking cessation studies. Participants were predominantly Spanish-speakers, evenly divided between men and women and relatively few indicated using traditional smoking cessation methods (e.g., groups or medication). This study demonstrates that substantial numbers of smokers from numerous countries seek Web-based smoking cessation resources and adds to the growing support for Web-assisted tobacco interventions as an additional tool to address the need for global smoking cessation efforts.
\end{abstract}


Keywords: Tobacco; smoking cessation; smoking behaviors; characteristics; Web-based; Internet; international; global.

\section{Introduction}

There are an estimated 1.3 billion smokers worldwide, of whom 650 million are expected to die prematurely of a tobacco-related disease [1]. Global mortality projections indicate that deaths attributable to tobacco use will soon be responsible for $10 \%$ of all deaths worldwide [2]. Without a doubt, tobacco use is a worldwide problem that warrants increased action focused on both tobacco control regulations and improving access to and utilization of smoking cessation interventions. Currently, there exist multiple ways to help individual smokers quit, but limited resources often impede access to these cessation aids, especially in some regions of the world.

To reach this large number of smokers across multiple countries, smoking cessation interventions are needed that can be disseminated widely and at low cost. The Internet is a viable means through which evidence-based smoking cessation interventions can be delivered [3]. The global impact of the Internet continues to grow each year, with recent reports showing that global usage is much higher than individual access [4]. Currently, countries in Asia, Europe, and the Americas report the highest access to and basic knowledge of the Internet (41.3\%, 24.8\%, 26.3\%, respectively) [4]. However, the percent of the total population of a given region that uses the Internet is highest for countries in the Americas $(73.1 \%)$ followed by countries in the regions of Oceania/Australia (57\%) and Europe (47.7\%). Although the rates of Internet use and access are primarily driven by certain countries within world regions (e.g., for the Americas, the USA and Canada have the greatest access), these data suggest that individuals will find a way to use the Internet even when access is not readily available.

The Internet is increasingly being recognized as a powerful tool for intervention and prevention program delivery [5]. Online interventions can reach individuals who live in remote areas where access to healthcare is limited [6] and are accessible to individuals who feel stigmatized by an illness [7]. Given the increasing number of Internet smoking cessation interventions, researchers need to examine the characteristics of individuals who decide to participate in formal outcome studies of such interventions. This will help develop evidence-based interventions for international samples of smokers using the Web to quit, as well as focus attention on those not reached, to develop campaigns that increase their participation.

A consistent pattern in the demographics of Web-based smoking cessation participants indicates that a majority of participants are White women and are highly educated. This pattern is evident in both US [8-10] and international samples [11,12]. Similar to the traditional non-Web-based samples of smokers, these smokers begin smoking between the ages of 14 to 16 years, became regular smokers at approximately 17 years, and smoke, on average, 17-20 cigarettes a day. They are interested in quitting smoking and almost all report previous quit attempts [8-12]. Thus, it appears as though smokers with a desire to quit report similar smoking characteristics, regardless of the setting where services are delivered or available.

There is an absence of reports focused on Spanish-speaking smokers, in particular, those who seek to quit via the Internet. In the USA, $15.2 \%$ of Latinos smoke [13]. Rates of tobacco use in Latin 
American countries are as high as $40.5 \%$ among adults and $37.9 \%$ among youths [14]. In Spain, approximately $30 \%$ of the population smokes and men between the ages of 25 and 44 years are the largest group of smokers [15]. Although there has been a global decline in tobacco use, increases in current smokers are projected to rise in developing countries. In the Americas, for example, the reported decline in the overall USA and Canadian population has been offset by projected increases in smoking expected in Spanish-speaking countries of Latin America [14]. Thus, there is a clear need to develop smoking cessation interventions that target and are accessible by Spanish-speaking smokers from all around the world.

The purpose of the current investigation is to present secondary analyses of demographic, smoking, and depression characteristics of a large global sample of English- and Spanish-speaking smokers who participated in Internet-based smoking cessation randomized trials.

\section{Experimental Section}

\subsection{Overview}

We analyzed all data available from visitors to a Website (www.dejardefumar.ucsf.edu or www.stopsmoking.ucsf.edu) conducting smoking cessation trials in Spanish and English during the period of March 1, 2002 to May 10, 2007. These automated, self-help smoking cessation Websites were designed to recruit Spanish- and English-speaking participants, obtain informed consent, collect assessment data, deliver an intervention, and conduct follow-up assessments. The sites yielded $20 \%$ quit rates at 12 months when participants with missing data at follow-up were assumed to be smoking. Complete details of the randomized trials are published elsewhere [16].

\subsection{Recruitment}

Participants for all four trials were recruited primarily through the World Wide Web. Press releases were sent to listservs, health information Websites, and written publications announcing the availability of the site and providing a link to it. Banner ads were distributed to sites that were willing to display it as a link to the study site. The studies' URL was registered with search engines (e.g. Google, Yahoo) and Web directories using keywords such as quit smoking and smoking cessation. A Google Adwords grant provided sponsored links to the study Website and yielded a large percent of the Website's traffic. Participants were also recruited via radio and television interviews announcing the study's URL.

Eligibility criteria included being 18 years or older, smoking five or more cigarettes daily, using e-mail at least once per week, and planning to quit smoking within the next 30 days. Participants meeting eligibility criteria were automatically directed to the Informed Consent to Participate approved by the Institutional Review Board at the University of California, San Francisco and the University of California, San Diego. A full description of the larger randomized trials has been published elsewhere $[16,17]$. 


\subsection{Measures}

Baseline instruments The baseline questionnaire included demographic items, questions pertaining to smoking patterns (e.g., age smoked first cigarette and became regular smoker), the Fagerström Test for Nicotine Dependence (FTND), the Major Depressive Episode (MDE) Screener, and the Center for Epidemiological Studies Depression Scale (CES-D).

The FTND [18] is a six-item self-report measure that assesses level of nicotine dependence. Its range is from 0-10 with higher scores indicating a higher level of dependence on nicotine. It has shown acceptable internal consistency $(\alpha=0.61)$ and is a reliable measure of nicotine dependence and a good predictor of smoking cessation success. A mean score of 5.8 has been reported among participants in traditional randomized controlled smoking cessation studies [19].

The MDE Screener [20-22] is a self-report questionnaire designed to assess for the presence of MDEs based on the nine symptom criteria outlined in the Diagnostic and Statistical Manual of Mental Disorders, $4^{\text {th }}$ edition [23]. Participants meet criteria for probable MDE if they indicate that they have experienced five or more of the nine symptoms during, at minimum, a two week period, and the symptoms interfered with their life or activities a lot; the symptoms must include either one or both of depressed mood and/or lack of interest/decreased pleasure. In a non-clinical sample of university students in Spain, the Spanish language version of the MDE Screener demonstrated good sensitivity ( $\kappa=0.969$; 95\% CI, 0.838-0.999), specificity ( $\kappa=0.967,95 \% C I, 0.948-0.980)$, and accuracy $(\kappa=0.968$, 95\% CI, 0.949-0.981) when compared to clinician diagnoses using the Structured Clinical Interview for DSM Disorders [22]. Additionally, the MDE Screener showed good predictive validity for quit rates in participants with past or current major depression [17,24].

The CES-D [25] is a self-report instrument that assesses for the presence of depressive symptoms during the previous week. Total scores range from 0-60, with higher scores indicating more severity of depressive symptoms. The national mean score in US adults [26] was 8.7 ( $S D=8.4$ ). CES-D scores have been shown to be related to smoking status in Latinos [27] and to predict the likelihood of quitting in earlier studies [17,28].

\subsection{Data Analyses}

All analyses were conducted with the SPSS statistical software version 15.0 for Windows (SPSS Inc., Chicago, Illinois, USA). Descriptive statistics and frequency estimates were calculated for all variables. Group comparisons were based on t-test and chi-square analyses. To make this report useful to clinicians, researchers, and policy makers from diverse regions of the world, data were categorized, analyzed, and presented according to World Health Organization (WHO) regional categories (see www.who.int for countries): Africa (AFR), Americas (AMR), Eastern Mediterranean (EMR), Europe (EUR), South-East Asia (SEAR), and Western Pacific (WPR). The WHO regions are comprised of the 192 United Nations Member States. To provide additional information at the country level, data were also categorized, analyzed and presented for countries with samples greater than 500 . 


\subsection{Sample}

Of the 71,344 individuals screened, 48,990 participants met eligibility criteria, and 22,204 consented to participate. To be included in the analyses, participants had to have answered the item "Where do you live?" Participants who did not have data on country of residence $(n=4515)$, and countries that are considered political territories $(n=89)$ or are not part of the WHO regional categorization $(n=15)$ were excluded from analyses. Thus, data from 17,579 (79\%) participants who consented to participate in one of four trials over a five year period were included in the final analyses.

\section{Results}

\subsection{Demographic Characteristics (Table 1)}

Table 1. Demographic characteristics by WHO regions, 2002-2007.

\begin{tabular}{|c|c|c|c|c|c|c|}
\hline & $\begin{array}{c}\text { AFR } \\
n=328\end{array}$ & $\begin{array}{c}\text { AMR } \\
n=10,673\end{array}$ & $\begin{array}{c}\text { EMR } \\
n=224\end{array}$ & $\begin{array}{c}\text { EUR } \\
n=5,478\end{array}$ & $\begin{array}{l}\text { SEAR } \\
n=467\end{array}$ & $\begin{array}{c}\text { WPR } \\
n=409\end{array}$ \\
\hline \multicolumn{7}{|c|}{ Number of countries represented / total countries comprising WHO region } \\
\hline & $22 / 46$ & $29 / 35$ & $18 / 21$ & $46 / 52$ & $7 / 11$ & $14 / 27$ \\
\hline & \multicolumn{6}{|c|}{ Percent } \\
\hline Female & 41.2 & 48.5 & 13.8 & 53.4 & 4.7 & 49.9 \\
\hline \multicolumn{7}{|l|}{ Language } \\
\hline English & 97.6 & 38.2 & 97.8 & 16.3 & 97.9 & 95.1 \\
\hline Spanish & 2.4 & 61.8 & 2.2 & 83.7 & 2.1 & 4.9 \\
\hline \multicolumn{7}{|l|}{ Marital Status } \\
\hline Single & 36.0 & 29.4 & 39.5 & 36.2 & 50.3 & 27.4 \\
\hline Married & 43.9 & 42.9 & 51.6 & 39.4 & 45.6 & 38.9 \\
\hline Separated & 1.5 & 5.3 & 0.4 & 4.2 & 0.9 & 6.1 \\
\hline Divorced & 5.5 & 9.2 & 3.6 & 3.6 & 1.3 & 9.0 \\
\hline Widowed & 0.9 & 1.3 & 0.0 & 0.5 & 0.2 & 1.5 \\
\hline Live with partner & 12.2 & 11.9 & 4.9 & 15.9 & 1.7 & 17.1 \\
\hline \multicolumn{7}{|l|}{ Education } \\
\hline$\leq 12$ years & 28.0 & 23.5 & 12.5 & 26.2 & 8.2 & 33.1 \\
\hline Some college & 36.0 & 34.3 & 14.3 & 30.3 & 9.2 & 24.2 \\
\hline College graduate & 28.4 & 29.5 & 45.5 & 29.1 & 48.6 & 32.2 \\
\hline Graduate degree & 7.6 & 12.7 & 27.7 & 14.4 & 34.0 & 10.5 \\
\hline \multicolumn{7}{|l|}{ Employment } \\
\hline Full time & 75.0 & 60.3 & 72.7 & 69.7 & 74.3 & 60.0 \\
\hline Part-time & 7.0 & 14.0 & 3.6 & 11.4 & 3.4 & 12.0 \\
\hline Not currently & 15.0 & 20.7 & 13.4 & 15.8 & 13.7 & 22.3 \\
\hline Not ever & 3.0 & 5.0 & 10.3 & 3.1 & 8.6 & 5.6 \\
\hline \multicolumn{7}{|c|}{ Income (USA dollars) } \\
\hline$<10,000$ & 33.8 & 32.4 & 43.1 & 19.3 & 58.5 & 15.3 \\
\hline $10,000-20,000$ & 16.1 & 17.2 & 14.5 & 27.3 & 18.4 & 11.8 \\
\hline $20,000-50,000$ & 23.5 & 25.4 & 22.1 & 35.5 & 13.1 & 38.1 \\
\hline $50,000-100,000$ & 20.2 & 17.4 & 14.0 & 13.4 & 7.6 & 25.5 \\
\hline$>100,000$ & 6.4 & 7.6 & 6.3 & 4.5 & 2.4 & 9.3 \\
\hline
\end{tabular}

Note: Data representative of participants who provided country of residence; WHO Regions: AFR - Africa; AMR - Americas; EMR - Eastern Mediterranean; EUR - Europe; SEAR - South-East Asia; WPR - Western Pacific 
Participants represented 157 countries. The majority were Spanish speakers (56.8\%) from AMR $(61.8 \%)$ and EUR $(83.7 \%)$. The sample was almost evenly split between men $(49.3 \%)$ and women (50.7\%), although men comprised a majority of the sample in EMR (86.2\%) and SEAR (95.3\%). Mean age at study entry was 37 years $(S D=10.4)$. A majority of participants were either married $(44 \%)$ or single $(30.4 \%)$ and employed full-time (63\%). Participants were well educated: $52.4 \%$ had attended some or completed college, while $11.7 \%$ had obtained professional degrees. The number of participants with college and professional degrees was highest for SEAR (48.6\% and 34\%, respectively) and EMR (45.5\% and $27.7 \%$, respectively); these regions also reported the lowest rate of participants with less than 12 years of education. The ethnic composition of participants was predominantly White and Hispanic/Latino. For all regions except EMR and SEAR, a majority of participants identified their ethnic/racial descent as White. Hispanic/Latino participants were predominantly from AMR and EUR. All group tests were significant at $p<0.0001$.

\subsection{Smoking Behaviors}

Participants' mean age when they smoked their first cigarette was $15.6(S D=3.7)$ and $18.3(S D=4.2)$ when they became regular smokers (Table 2).

Table 2. Smoking behavior and depression characteristics by WHO region.

\begin{tabular}{|c|c|c|c|c|c|c|}
\hline & $\begin{array}{c}\text { AFR } \\
n=328\end{array}$ & $\begin{array}{c}\text { AMR } \\
n=10,673\end{array}$ & $\begin{array}{c}\text { EMR } \\
n=224\end{array}$ & $\begin{array}{c}\text { EUR } \\
n=5,478\end{array}$ & $\begin{array}{l}\text { SEAR } \\
n=467\end{array}$ & $\begin{array}{c}\text { WPR } \\
n=409\end{array}$ \\
\hline \multicolumn{7}{|c|}{$\begin{array}{c}\text { Smoking history } \\
\text { Mean }(S D)\end{array}$} \\
\hline Age & $34.7(10.2)$ & $37.6(11.2)$ & $32.4(9.0)$ & $34.4(9.3)$ & $31.2(8.2)$ & $37.6(11.2)$ \\
\hline Age, first & $16.1(3.4)$ & $15.6(3.7)$ & $17.3(4.0)$ & $15.3(3.1)$ & $18.5(3.6)$ & $15.3(3.4)$ \\
\hline Age, regular & $18.6(3.9)$ & $18.3(4.6)$ & $19.8(3.7)$ & $17.8(3.5)$ & $20.6(3.7)$ & $17.8(4.1)$ \\
\hline Cigarettes/day & $20.8(10.7)$ & $19.9(10.4)$ & $20.6(10.6)$ & $22.6(10.8)$ & $13.3(7.4)$ & $20.2(10.6)$ \\
\hline FTND score & $5.7(2.5)$ & $5.2(2.5)$ & $5.5(2.4)$ & $5.7(2.4)$ & $4.4(2.4)$ & $5.6(2.5)$ \\
\hline Quit confidence & $7.0(2.2)$ & $7.1(2.1)$ & $6.5(2.4)$ & $6.9(2.0)$ & $6.9(2.3)$ & $6.9(2.0)$ \\
\hline \multicolumn{7}{|c|}{ Quit methods used in last 6 months (\%) } \\
\hline \multicolumn{7}{|l|}{ Methods } \\
\hline NRT & 13.7 & 16.1 & 14.5 & 16.1 & 8.1 & 24.2 \\
\hline Antidepressant & 13.7 & 5.8 & 2.3 & 4.4 & 2.6 & 4.8 \\
\hline Alternative & 3.2 & 3.2 & 2.7 & 3.2 & 0.2 & 6.8 \\
\hline Self-help & 7.7 & 7.1 & 6.3 & 10.4 & 8.1 & 13.6 \\
\hline SC group & 2.2 & 2.7 & 0.0 & 2.2 & 0.4 & 2.0 \\
\hline Other & 4.5 & 3.1 & 4.1 & 3.5 & 3.1 & 3.8 \\
\hline None & 55.0 & 62.0 & 70.1 & 60.2 & 77.5 & 44.7 \\
\hline \multicolumn{7}{|c|}{ Depression history (\%) } \\
\hline \multicolumn{7}{|c|}{ Major Depressive Episode (MDE) } \\
\hline No MDE & 69.3 & 62.9 & 60.7 & 63.7 & 64.1 & 63.6 \\
\hline Past MDE & 13.2 & 15.8 & 12.3 & 19.1 & 10.6 & 20.5 \\
\hline Current MDE & 17.5 & 21.2 & 26.9 & 17.2 & 25.3 & 15.8 \\
\hline CES-D $(M, S D)$ & $17.6(12.8)$ & $17.5(12.2)$ & $20.7(12.5)$ & $15.8(11.9)$ & $19.5(12.0)$ & $17.0(12.4)$ \\
\hline
\end{tabular}

Note: WHO Regions: AFR - Africa; AMR - Americas; EMR - Eastern Mediterranean; EUR Europe; SEAR - South-East Asia; WPR - Western Pacific; CES-D - Center for Epidemiologic Studies - Depression Scale; FTND - Fagerström Test for Nicotine Dependence; NRT - Nicotine Replacement Therapy; nicotine gum, patch, inhaler, spray; Antidepressant - Bupropion, other antidepressant; Alternative - hypnosis, acupuncture, motivational tape; SC - Smoking cessation. 
The average FTND score was $5.4(S D=2.4)$. A similar pattern of smoking behavior was reported across all the individual regions. Interestingly, however, participants in SEAR were younger $(M=31.2$, $S D=8.2)$, reported an older average age when their fist cigarette was smoked $(M=18.5, S D=3.6)$ and when they became regular smokers $(M=20.6, S D=3.7)$, but a lower mean number of cigarettes smoked per day $(M=13.3, S D=7.4)$ and FTND score $(M=4.4, S D=2.4)$. All group comparisons were highly significant $(p<0.0001)$.

More than half of all participants $(60.7 \%)$ had not used a smoking cessation aid in the previous 6 months. Of those who did use a smoking cessation method, use of NRT aids (gum, inhaler, patch, spray) in the previous 6 months was greater for participants from WPR (24.2\%) and least by participants in SEAR (8.1\%). Participants in AFR endorsed the highest use of antidepressants (13.7\%) to quit smoking, while a high rate of participants in EMR and SEAR indicated that they had not used any methods to quit during the previous six months ( $70.1 \%$ and $77.5 \%$, respectively).

\subsection{Depression History}

Forty-seven percent reported elevated levels of depressive symptoms (CES-D score>16) during the week prior to study entry. Thirty-seven percent endorsed a history of MDE with similar reports across each of the regions. However, the distribution of current and past MDE between the samples differed such that participants from EMR reported the highest rate of current MDE (26.9\%) and WPR endorsed the lowest rate $(15.8 \%)$. Regarding past MDE, the rate was highest for participants in WPR $(20.5 \%)$ and lowest for those residing in countries in SEAR (10.6\%).

\subsection{Smoking Behaviors and Depression History by Country}

An examination of the country specific characteristics revealed similar patterns as those represented by each of the WHO regions. Of the six countries with a sample of 500 or more (see Table 3), participants from the USA included more women and were predominantly English-speaking. The remaining samples were predominantly Spanish-speaking and although the Spain sample was comprised of $53.3 \%$ women, more than $50 \%$ of the samples from Argentina, Chile, Mexico, and Venezuela were men. The USA and Mexico reported the highest rate of NRT used in the previous 6 months (23.5\% and 22.5\%, respectively), while Argentina reported a very low rate (4.5\%). Antidepressant medications were least used in Mexico (1.4\%) and most frequently used in the USA $(9.8 \%)$. A notable difference was reported in the proportion of smokers who did not use any smoking cessation aids in the previous 6 months - less than $50 \%$ of the US sample. In contrast, it ranged as high as $78.7 \%$ in Chile to $62.9 \%$ in Spain.

Reports on depression history were most similar for the Spain and USA samples, in comparison to the samples from Latin America. A remarkably high and constant proportion of smokers (between $33.9 \%$ and 39.2\%) screened positive for at least one MDE. However, smokers in Latin America were more likely to report a current MDE at study entry (22\% to 25\%) than those in the USA (16.8\%) and Spain (17.3\%). Consequently, the latter reported higher rates of past MDE. Mean depression symptom scores were in the elevated range for all six countries. All group comparisons were highly significant $(p<0.0001)$. 
Table 3. Smoking behavior and depression characteristics by countries with 500 or more participants.

\begin{tabular}{|c|c|c|c|c|c|c|}
\hline Country & $\begin{array}{c}\text { Spain } \\
n=4,514\end{array}$ & $\begin{array}{c}\text { USA } \\
n=3,852\end{array}$ & $\begin{array}{l}\text { Argentina } \\
n=2,005\end{array}$ & $\begin{array}{c}\text { Mexico } \\
n=1,605\end{array}$ & $\begin{array}{c}\text { Chile } \\
n=882\end{array}$ & $\begin{array}{c}\text { Venezuela } \\
n=531\end{array}$ \\
\hline$\%$ Female & 53.3 & 60.4 & 44.7 & 36.2 & 45.0 & 46.1 \\
\hline \multicolumn{7}{|l|}{ Language } \\
\hline$\%$ English & 1.4 & 96.2 & 0.9 & 3.7 & 0.9 & 2.4 \\
\hline$\%$ Spanish & 98.6 & 3.8 & 99.1 & 96.3 & 99.1 & 97.6 \\
\hline \multicolumn{7}{|c|}{$\begin{array}{c}\text { Smoking history } \\
\text { Mean }(S D)\end{array}$} \\
\hline Age & $34.5(9.1)$ & $39.3(11.6)$ & $36.7(10.8)$ & $36.5(11.2)$ & $35.4(10.8)$ & $37.8(10.4)$ \\
\hline Age, first & $15.3(3.0)$ & $15.5(4.4)$ & $15.7(3.2)$ & $15.7(3.3)$ & $15.4(2.9)$ & $16.2(3.6)$ \\
\hline Age, regular & $17.8(3.5)$ & $18.1(4.6)$ & $18.7(4.5)$ & $19.0(4.5)$ & $18.9(4.4)$ & $19.6(5.3)$ \\
\hline Cigarettes/day & 23.0(10.9) & $20.3(10.0)$ & $23.0(11.0)$ & $17.4(9.3)$ & $17.1(8.1)$ & $22.1(13.2)$ \\
\hline FTND score & $5.8(2.4)$ & $5.5(2.4)$ & $5.4(2.5)$ & $4.8(2.6)$ & $4.7(2.5)$ & $5.8(2.5)$ \\
\hline \multicolumn{7}{|c|}{ Quit methods used in last 6 months (\%) } \\
\hline \multicolumn{7}{|l|}{ Methods } \\
\hline NRT & 13.8 & 23.5 & 4.5 & 22.5 & 7.6 & 13.5 \\
\hline Antidepressant & 4.6 & 9.8 & 4.7 & 1.4 & 3.0 & 5.3 \\
\hline Alternative & 2.9 & 4.4 & 3.3 & 1.3 & 1.7 & 3.4 \\
\hline Self-help & 10.1 & 10.0 & 5.2 & 4.7 & 4.6 & 8.0 \\
\hline SC group & 2.1 & 3.7 & 3.6 & 1.2 & 1.0 & 0.8 \\
\hline Other & 3.5 & 3.7 & 3.1 & 1.9 & 3.4 & 3.1 \\
\hline None & 62.9 & 44.9 & 74.6 & 67.0 & 78.7 & 65.8 \\
\hline \multicolumn{7}{|c|}{ Depression history $(\%)$} \\
\hline \multicolumn{7}{|c|}{ Major Depressive Episode (MDE) } \\
\hline No MDE & 63.4 & 63.7 & 61.2 & 66.1 & 60.8 & 63.3 \\
\hline Past MDE & 19.4 & 19.6 & 14.6 & 11.4 & 15.9 & 11.7 \\
\hline Current MDE & 17.3 & 16.8 & 24.3 & 22.5 & 23.3 & 25.0 \\
\hline CES-D $(M, S D)$ & $15.8(12.0)$ & $16.2(11.8)$ & $18.7(12.3)$ & $17.7(12.7)$ & $18.4(12.3)$ & $19.0(12.6)$ \\
\hline
\end{tabular}

Note: WHO Regions: AMR - Americas; EUR - Europe; CES-D - Center for Epidemiologic Studies - Depression Scale; FTND - Fagerström Test for Nicotine Dependence; NRT - Nicotine Replacement Therapy; nicotine gum, patch, inhaler, spray; Antidepressant - Bupropion, other antidepressant; Alternative - hypnosis, acupuncture, motivational tape; SC - Smoking cessation.

Sample sizes greater than 100 and less than 500 were represented by countries in AFR, AMR, EUR, SEAR, and WPR regions; none of the EMR countries exceeded a sample size of 100. India, South Africa, and Australia represented a majority of the sample within their respective regions $(92.5 \%$, $83.2 \%$, and $56.2 \%$, respectively). Greater than $50 \%$ were female in samples from Canada, Uruguay, Ireland, U.K., and Australia. As expected, countries in Latin America were almost entirely comprised of Spanish-speakers, while the opposite was true of the remaining countries with samples from South Africa and India including zero Spanish-speakers. Smoking behaviors were relatively similar across countries, with the exception of reported smoking cessation aids used in the previous 6 months. The U.K., Canada, Ireland, and Australia samples were most alike in their use of methods: they reported the highest percentage of participants to use NRT aids $(33.9 \%, 32.5 \%, 28.5$, and $23.3 \%$, respectively) and the lowest rate of using nothing in the six months prior to study entry $(38.6 \%, 35.5 \%, 37.4 \%$, and $38.6 \%$, respectively); additionally, they reported higher rates of using self-help methods (11.7\%, 
$10.0 \%, 15.6 \%$, and $17.2 \%$, respectively). The Peru sample represented the largest percentage of participants who had not used any methods to quit smoking in the previous 6 months $(83.2 \%)$.

Participants from Colombia and Peru reported the highest rates of MDE history (45\% and 40.8\%, respectively), including current $\operatorname{MDE}$ (32.2\% and 26.8\%, respectively). Past MDE was highest in Australia (23.1\%) and Canada (22.5\%) and lowest in South Africa (12.9\%), India (12.9\%), and Colombia (12.8\%).

\section{Discussion}

This investigation examined demographic, smoking and depression characteristics of a large international sample of English and Spanish-speaking smokers attempting to quit by participating in Internet-based smoking cessation randomized trials. Smokers in the current investigation were similar to community samples of smokers [8], smokers enrolled in traditional, face-to-face smoking cessation programs [29], smokers who use the Internet [10-12] and Internet users [30] in terms of gender, age, education, nicotine dependence, and number of cigarettes smoked currently. Smoking patterns were very similar across regions of the world among persons who speak English or Spanish, suggesting that smoking cessation methods might work similarly in smokers from different regions who share similar characteristics and who turn to the Internet for help in quitting. In this report, data are presented by WHO regional categorization and by country for larger sub-samples. We chose to present the data in this format to support international efforts to adapt Internet interventions to the characteristics of smokers who seek help from the Web to quit and to develop means to reach those who do not currently use these methods. We believe international health agencies currently underutilize the Web for tobacco control and other health interventions. Increasing Internet access focused on such health interventions would help scale up efforts to prevent unnecessary morbidity and mortality.

Participants from the Eastern Mediterranean and South-East Asian regions were most alike in gender composition, marital status and education. Differences between the regions can potentially be explained by the greater prevalence of male smokers [31,32] and tobacco use being viewed as a traditionally male behavior $[33,34]$ in countries within these regions. Ten percent of women compared to $50 \%$ of men smoke in the Eastern Mediterranean [32]. Attitudes about female smoking behavior suggest greater social disapproval [35] and greater permissiveness towards alternative forms of tobacco consumption (e.g., water pipes) among family members of female tobacco users [34].

Of the 157 countries represented in this investigation, English is the national or official language of 30 countries and Spanish of 20. Other than the samples from South Africa and India, all of the countries profiled included English- and Spanish-speaking smokers, regardless of the country's dominant language, suggesting the possibility that Internet-based cessation trials can provide a service to smokers in countries where services may not be available in their language of preference. We did not ascertain participants' native language and the country affiliation refers to where participants reside, therefore, it is difficult to assess whether this assumption is accurate. In fact, many of the participants may be expatriates from English or Spanish-speaking countries or they may have sufficient knowledge of a non-native language to be able to use the Internet site. Nonetheless, it appears as though this smoking cessation Website reached smokers who were interested in quitting and who resided in countries where languages other than English and Spanish are the official languages. 
Participants began smoking around the age of 15 , became regular smokers three years later and currently smoked approximately 20 cigarettes a day. South-East Asian smokers were older when they smoked their first cigarette and when they became regular smokers, indicated fewer daily cigarettes smoked and endorsed a lower nicotine dependence score. This latter finding makes sense given their overall younger age, which translates to fewer years smoking and, possibly, less addiction. The study Website that recruited these participants is intended for individuals seeking to quit smoking cigarettes and does not address other forms of tobacco products. In India, the largest country represented in this region, bidis, cigarettes, and chewing tobacco are the more common forms of tobacco consumption. Approximately $65 \%$ of men and $33 \%$ of women use tobacco, but $35 \%$ and $3 \%$, respectively, smoke [36]. The level of nicotine dependence in this investigation reflects dependence among cigarette smokers similar to that found in traditional smoking cessation studies.

Traditional smoking cessation methods were actually used by very few smokers (e.g., NRT and groups) and there were disparities in terms of utilization of smoking cessation methods between high, middle and low income countries. However, 27.5\% more smokers reported a quit attempt than reported the use of smoking cessation aids in the previous 6 months, suggesting that a sizable number of participants may have used nothing (i.e., cold turkey) in their quit efforts. The countries with the largest percentage of participants using NRTs in the previous six months included the USA, Mexico, U.K., Canada, Ireland, and Australia. In these countries, NRTs are more accessible given that they are available over the counter and smokers from some of these countries are reimbursed by their country's national health plans [14]. Except for participants from Mexico, fewer than half of participants from these countries indicated using nothing to quit, suggesting that they may have greater access to other types of cessation aids in addition to NRTs. Self-help methods were also popular among participants; however, it is unclear what types of self-help methods were used.

There is evidence that depressed individuals are more likely to begin or continue smoking and less likely to quit [37] and, consequently, tend to report higher rates of smoking behavior and nicotine dependence [38,39]. Similarly, the risk of depression onset is higher for heavy smokers than for nonsmokers [40] and for current smokers versus ex-smokers [41]. Data from this investigation demonstrated that depression symptoms and clinical-level depression were very prevalent in smokers across the world. Almost 50\% of the sample endorsed elevated symptoms of depression during the previous two weeks, with over a third meeting diagnostic criteria for a lifetime MDE. The rate of screening positive for current MDE reported by the entire sample was consistent with rates of current MDE among smokers in a multinational sample [41] and smokers at the start of a smoking cessation treatment program [42].

\subsection{Limitations}

There are several limitations to the data presented in this report. First, the data are representative of a specific sample of smokers who searched the Web for smoking cessation resources and were willing to participate in an online smoking cessation study and able to read in English or Spanish. Although this report included smokers from 157 countries, this report solely described characteristics of smokers who resided in countries included in the WHO regions. This study excluded smokers who reported fewer than five cigarettes per day, who are under the age of 18, who do not have Internet or email access, who are not interested in quitting, and who reside in countries or territories not included in 
WHO regional categorizations. Second, the sample likely had an overrepresentation of highly educated smokers who may have greater resources, including access to smoking cessation aids and interventions. Smokers with limited resources may not be aware or have access to opportunities available on the Internet to improve their health. Third, a significant portion of the English-speaking sample was from the USA, while a greater proportion of Spanish-speaking participants were from Spain. Although we obtained data on ethnic and racial background, it is difficult to draw conclusions about the cultural influences on smoking behavior and depression history given the complexity of cultural factors and its influence on behavior. Finally, this report does not include analyses on the costeffectiveness of Web-based smoking cessation trials, which is an important factor to consider when designing such interventions.

\section{Conclusion}

This investigation demonstrates that smokers from many countries around the world are interested in participating in Web-based smoking cessation studies. Although they are from diverse cultural and linguistic backgrounds, they share similar smoking behavioral patterns. Smokers in this investigation reported characteristics that were consistent with smokers in traditional smoking cessation studies and Internet users. The results highlight the need to provide Web access to less educated smokers and to test whether these Internet interventions are also effective with populations with lower socioeconomic and educational levels. Considerable inequalities in reported use of traditional smoking cessation aids were reflected in this global sample. Web interventions that are able to achieve smoking cessation rates comparable to traditional smoking cessation methods should be championed by policy makers as an additional tool for global smoking cessation efforts.

\section{Acknowledgments}

The work described in this manuscript was performed at the University of California, San Francisco, and the University of California, San Diego. This research was supported by grants 13RT0050 from the Tobacco-Related Disease Research Program (Muñoz), TW05935 from the Tobacco Research Network Program, Fogarty International Center, National Institute of Health (Pérez-Stable), P50 DA09253 from the National Institute of Drug Abuse (Delucchi), F32 MH07771 from the National Institute of Mental Health (Barrera), and by an infrastructure grant from the University of California Committee on Latino Research to the University of California/San Francisco General Hospital Latino Mental Health Research Program. The authors thank the Center for Health and Community (Nancy Adler, Ph.D., Director) for providing office space and additional resources to target Latino smokers, Leslie Lenert, M.D. for his collaboration in the initial Website and randomized trial, Carlos Penilla, M.A. for his commitment and dedication as the Project Coordinator, Veronica Pitbladdo, B.A. and Ruchita Patel, B.A. for their assistance with the manuscript, and the many Research Assistants who volunteered their time and efforts toward maintaining the day-to-day tasks of the randomized trials. Finally, the authors thank Google, Inc. for a generous Google Adwords grant to assist with recruitment. 


\section{References and Notes}

1. World Health Organization. Facts and figures about tobacco. First Conference of Parties to the WHO Framework Convention on Tobacco Control. Available at http://www.who.int/tobacco/fctc/tobacco\%20factsheet\%20for\%20COP4.pdf (accessed May 29, 2008).

2. Mathers, C.D.; Loncar, D. Projections of global mortality and burden of disease from 2002 to 2030. PloS Med. 2006, 3, 2011-2030.

3. Walters, S.T.; Wright, J.A.; Shegog, R. A review of computer and Internet-based interventions for smoking behavior. Addict. Behav. 2006, 31, 264-277.

4. Internet World Stats. Internet usage statistics - The Internet big picture world Internet users and population stats. Available at http://www.internetworldstats.com/stats.htm (accessed May 14, 2008).

5. Levy, J.A.; Strombeck, R. Health benefits and risks of the Internet. J. Med. Syst. 2002, 26, 495510.

6. Schopp, L.H.; Demiris, G.; Glueckauf, R.L. Rural backwaters or front-runners? Rural telehealth in the vanguard of psychology practice. Prof. Psychol. Res. Pr. 2006, 37, 165-173.

7. Griffiths, K.M.; Christensen, H.; Jorm, A.F.; Evans, K.; Groves, C. Effect of Web-based depression literacy and cognitive-behavioural therapy interventions on stigmatising attitudes to depression: Randomised controlled trial. Br. J. Psychiatry 2004, 185, 342-349.

8. Graham, A.L.; Bock, B.C.; Cobb, N.K.; Niaura, R.; Abrams, D.B. Characteristics of smokers reached and recruited to an internet smoking cessation trial: A case of denominators. Nicotine Tob. Res. 2006, 8, S43-S48.

9. Lemmonds, C.A.; Mooney, M.; Reich, B.; Hatsukami, D. Characteristics of cigarette smokers seeking treatment for cessation versus reduction. Addict. Behav. 2004, 29, 357-364.

10. Stoddard, J.L.; Auguston, E.M. Smokers who use Internet and smokers who don't: Data from the Health Information and National Trends Survey (HINTS). Nicotine Tob. Res. 2006, 8, S77-S85.

11. Etter, J.F. Comparing the efficacy of two Internet-based, computer-tailored smoking cessation programs: A randomized trial. J. Med. Internet Res. 2005, 7, e2.

12. West, R.; Gilsenan, A.; Coste, F.; Zhou, X.; Brouard, R.; Nonnemaker, J.; Curry, S.J.; Sullivan, S.D. The ATTEMPT cohort: A multi-national longitudinal study of predictors, patterns and consequences of smoking cessation; introduction and evaluation of internet recruitment and data collection methods. Addiction 2006, 101, 1352-1361.

13. Center for Disease Control and Prevention. Adult cigarette smoking in the United States: Current estimates-fact sheet. Available at http://www.cdc.gov/tobacco/data_statistics/Factsheets/adult_cig smoking.htm (accessed February 6, 2008).

14. Mackay, J.; Ericksen, M. The tobacco atlas. World Health Organization: Geneva, Switzerland. Available at http://who.int/tobacco/resources/publications/tobacco_atlas/en/ (accessed March 29, 2008).

15. Instituto Nacional de Estadística. Encuesta Nacional de Salud de España 2006 [National Health Survey of Spain 2006]. Available at 
http://www.msc.es/estadEstudios/estadisticas/encuestaNacional/encuesta2006.htm ～(accessed February 6, 2008).

16. Muñoz, R.F.; Barrera, A.Z.; Penilla, C.; Delucchi, K.; Pérez-Stable, E.J. Worldwide Spanish/English Internet smoking cessation trial. Nicotine Tob. Res. In press.

17. Muñoz, R.F.; Lenert, L.L.; Delucchi, K.; Stoddard, J.; Pérez, J.E.; Penilla, C.; Pérez-Stable, E.J. Toward Evidence-based Internet Interventions: A Spanish/English Web Site for International Smoking Cessation Trials. Nicotine Tob. Res. 2006, 8, 77-87.

18. Heatherton, T.F.; Kozlowski, L.T.; Frecker, R.C.; Fagerström, K.O. The Fagerstrom Test for Nicotine Dependence: A revision of the Fagerström Tolerance Questionnaire. Br. J. Addict. 1991, 86, 1119-1127.

19. Tsoh, J.Y.; Humfleet, G.L.; Muñoz, R.F.; Reus, V.I.; Hartz, D.T.; Hall, S.M. Development of major depression after treatment for smoking cessation. Am. J. Psychiatry 2000, 157, 368-374.

20. Muñoz, R.F. The Major Depressive Episode (MDE) Screener. Available at http://www.medschool.ucsf.edu/latino/manuals.aspx (accessed July 24, 2008).

21. Miller, W.R.; Muñoz, R.F. Controlling your drinking; Guilford: New York, USA, 2005.

22. Vázquez, F.L.; Muñoz, R.F.; Blanco, V.; López, M. Validation of Muñoz's Mood Screener in a nonclinical Spanish population. Eur. J. Psychol. Assess. 2008, 24, 57-64.

23. American Psychiatric Association. Diagnostic and Statistical Manual of Mental Disorders, $4^{\text {th }}$ Edition; American Psychiatric Association: Washington, D.C., USA, 1994.

24. Muñoz, R.F.; Marín, B.; Posner, S.F.; Pérez-Stable, E.J. Mood management mail intervention increases abstinence rates for Spanish-speaking Latino smokers. Am. J. Community Psychol. 1997, 25, 325-343.

25. Radloff, L.S. The CES-D Scale: A self-report depression scale for research in the general population. Appl. Psychol. Meas. 1977, 1, 385-401.

26. Sayetta, R.B.; Johnson, D.P. Basic data on depressive symptomatology: United States, 1974-1975. Vital and Health Statistics; Series 11, Number 216 (DHEW Publication No. PHS 80-1666); National Center for Health Statistics: Hyattsville, M.D., USA, 1978.

27. Pérez-Stable, E.J.; Marín, G.; Marín, B.; Katz, M.H. Depressive symptoms and cigarette smoking among Latinos in San Francisco. Am. J. Public. Health 1990, 80, 1500-1502.

28. Anda, R.F.; Williamson, D.F.; Escobedo, L.G.; Mast, E.E.; Giovino, G.A.; Remington, P.L. Depression and the dynamics of smoking: A national perspective. JAMA 1990, 12, 1541-1545.

29. Le Faou, A.L.; Scemama, O.; Ruelland, A.; Ménard, J. Characteristics of smokers seeking smoking cessation services: The CDT programme. Rev. Mal. Respir. 2005, 22, 739-750.

30. Ono, H.; Zavodny, M. Gender and the Internet. Social Science Quarterly 2003, 84, 111-121.

31. Jha, P.; Chaloupka, F.J.; Carrao, M.; Jacob, B. Reducing the burden of smoking world-wide: Effectiveness of interventions and their coverage. Drug Alcohol Rev. 2006, 25, 597-609.

32. Tobacco control country profiles; Shafey, O., Dolwick, S., Guidon, G.E., Eds.; American Cancer Society: Atlanta, GA, USA. Available at http://who.int/tobacco/gobal_data/country_profiles (accessed March 29, 2008).

33. Mackay, J.; Amos, A. Women and tobacco. Repirology 2003, 8, 123-130.

34. World Health Organization. Gender and tobacco in the Eastern Mediterranean region. Available at http://emro.who.int/ghd/PDF/gender_tobacco.pdf (accessed May 29, 2008). 
35. Sarraf-Zagedan, N.; Boshtam, M.; Shahrokhi, S.; Naderi, G.A.; Asgary, S.; Shahparian, M.; Tafazoli, F. Tobacco use among Iranian men, women and adolescents. Eur. J. Public Health 2004, 14, 76-78.

36. Chaly, P.E. Tobacco control in India. Indian J. Dent. Res. 2007, 18, $2-5$.

37. Murphy, J.M.; Horton, N.J.; Monson, R.R.; Laird, N.M.; Sobol, A.M.; Leighton, A.H. Cigarette smoking in relation to depression: Historical trends from the Stirling County Study. Am. J. Psychiatry 1991, 160, 1663-1669.

38. John, U.; Meyer, C.; Rumpf, H.J.; Hapke, U. Smoking, nicotine dependence and psychiatric comorbidity--a population-based study including smoking cessation after three years. Drug Alcohol Depend. 2004, 76, 287-295.

39. Lee, R.S.; Staten, R.R.; Danner, R.W. Smoking and depressive symptoms in a college population. J. Sch. Nurs. 2005, 21, 229-235.

40. Klungsøyr, O.; Nygard, J.F.; Sorensen, T.; Sandanger, I. Cigarette smoking and incidence of first depressive episode: An 11-year, population-based follow-up study. Am. J. Epidemiol. 2006, 163, 421-432.

41. Wiesbeck, G.A.; Kuhl, H.-C.; Yaldizli, Ö.; Wurst, F.M. Tobacco Smoking and Depression Results from the WHO/ISBRA Study. Neuropsychobiology 2008, 57, 26-31.

42. Lugoboni, F.; Quaglio, G.; Pajusco, B.; Mezzelani, P.; Lechi, A. Association between depressive mood and cigarette smoking in a large Italian sample of smokers intending to quit: Implications for treatment. Intern. Emerg. Med. 2007, 2, 196-201.

(C) 2009 by the authors; licensee Molecular Diversity Preservation International, Basel, Switzerland. This article is an open-access article distributed under the terms and conditions of the Creative Commons Attribution license (http://creativecommons.org/licenses/by/3.0/). 